\title{
The use of a digital controller in the loading system of the test bench to improve the accuracy of simulating the modes of oil pumping units
}

\author{
Timur Petrov ${ }^{1, *}$, Vladimir Kornilov ${ }^{1}$, AlfredSafin ${ }^{1}$, Nikita Kuvshinov $^{1}$, Alexey Tsvetkov ${ }^{1}$, and Ramil Gibadullin ${ }^{1}$ \\ ${ }^{1}$ Kazan State Power Engineering University, Kazan, Russia
}

\begin{abstract}
Modern trends in the development of technologies are based on the need to conduct experimental studies of the developed equipment in laboratory conditions with the maximum approximation of operating modes to real ones. Such studies are impossible without the development of specialized stands with test automation systems. In modern test equipment systems, devices are often used to create a mechanical load on the shaft of the electric motor under study. As such a device, a system of frequency converter - load asynchronous electric motor has been proposed and implemented, which has been tested at the test bench and has proven itself from the best side in comparison with traditional circuits using DC motors.
\end{abstract}

\section{Introduction}

In the development and design of electric drives for oil pumping units used in installations, the problem arises of developing analytical and experimental methods and hardware and software for monitoring the performance of electric drives based on permanent magnet synchronous motors in normal and emergency (critical) operating modes. One of the possible ways to solve this problem is long-term field tests on existing installations, which entails the need to attract large material resources and attract a large number of specialists involved in setting up individual systems that are part of the electric drive. As an alternative solution, it is proposed to conduct research and testing of electric drives on experimental stands, which make it possible to bring working conditions closer to real field tests $[1,2,3]$.

The use of a load asynchronous electric motor as part of the test bench revealed a number of disadvantages: overheating of the asynchronous electric motor operating in the opposing mode and low accuracy of creating the load torque and the speed of the system response [4].

The problem of overheating of the load motor is solved by transferring the frequency converter to the direct torque control mode. At the same time, a significant decrease in the motor current and poor stabilization of the temperature regime were detected $[5,6]$.

The article will talk about the developed stand, about its structure and features, and the shortcomings that have arisen. Some of these problems can be solved by using a digital regulator, the advantages of which will be presented in the article. The results from the introduction of this regulator into the stand will also be demonstrated.

\section{Test bench composition}

The low accuracy and response speed of the system were increased by introducing feedback and a proportionalintegral-derivative controller into the stand control system, presented in Figure $1[7,8,9]$.

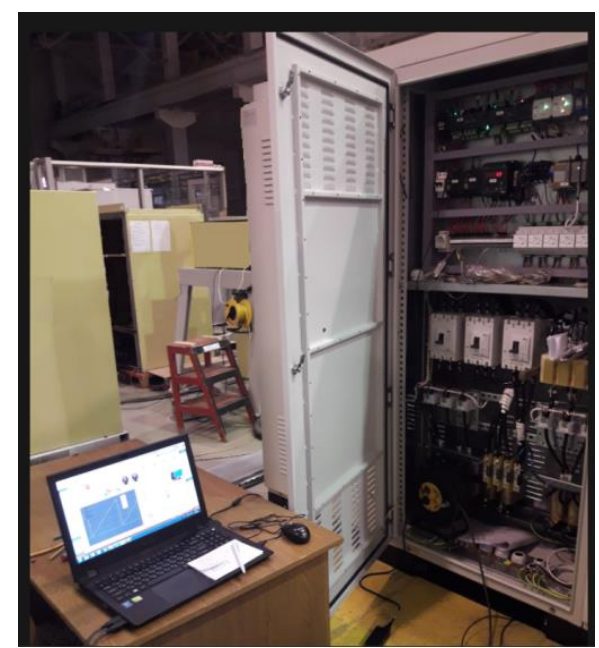

Fig. 1.Experimental stand for electric motors.

Standard stands for electric motors include a power system consisting of a power drive and load control system. The power system is built on the basis of frequency converters with their control via digital, analog and discrete channels. Analog and discrete control channels in combination with digital ones are used to increase the reliability of the loading system control. 
The control system of the experimental stand includes channels for measuring such quantities as frequency and current, supply voltage, angular frequency of rotation of the motor output shaft, and mechanical torque on the shaft. The ambient temperature is also measured in the compartments of the control station, the electric motor, the housing and in the stator windings. It is possible to use channels to control actuators and channels to generate digital signals from simulated sensors.

The operating modes of the load frequency converter are controlled via discrete channels implemented using a discrete output module.

During testing, three modes are used:

1. "Start / Stop" for switching on and off the operating mode of the converter;

2. "Forward / Backward" to change the direction of rotation of the engine, that is, the load motor either loads the tested motor (counter-switching mode), or accelerates it to simulate a large imbalance of the oil pumping unit;

3. "Speed / Torque Control Select" to change the test process mode to either accelerate or torque load the motor under test.

Separately, a test for determining the EMF of rotation should be highlighted, when the loading motor acts as a drive motor, rotating the rotor of a de-energized motor.

The mode of imitation of a large unbalance of the rocking machine is used to practice methods of bypassing the situation that occurs when the balance bar moves upwards, and the crank weights down, and when the weights are incorrectly positioned, causing the drive motor to accelerate. In this situation, the motor rotates at a frequency higher than the frequency of the supply from the frequency converter. In this case, the voltage of the DC link of the frequency converter is increased and reset to the braking resistor in order to avoid damage to the power circuit elements. Without a braking resistor, the DC link voltage of the adjustable frequency drive rises to the specified limits, after which the protection is activated and the motor is shut off. It is possible to avoid emergency shutdown by applying the method of shortterm increase in the speed of rotation of the electric motor until the end of lowering the loads.

To change the modes of simulating the state of the rocking machine, the experimenter has the ability to change the type of the affected motor. In this case, it can be the operating modes of the pumping unit with a slight imbalance, with strong balancing, with a breakage of rods or a strong influence of gas and with a pump jam. The experimenter has the ability to change the maximum, minimum values and the swing period. The selected type of load type should show the control system of the control station of the engine under test for one or another malfunction, checking the adequacy of the embedded control algorithms. The control system, at the same time, must respond to a change in the state of the well and, if necessary, take action to prevent an emergency.

In the control window of the hardware-controlled software complex, the main parameters are visualized and the stand operating modes are controlled. The program implements a number of protective mechanisms related to monitoring the maximum currents and the rate of temperature change. For example, when the output current of the load converter is exceeded, the system automatically reduces the torque on the motor shaft. The system responds in the same way to a sharp decrease in engine speed $[10,11]$.

All measured parameters are visualized using a system of virtual instruments, converting a digital value with the required dimension and in the form of dial gauges [12,13].

The developed virtual devices have a wide range of settings, allowing them to be used to solve any problem. In the devices, the minimum, maximum value, the step of the scale grid, the dimension of the value of the duplicate digital record are configured. Arrow virtual devices have the ability to display the measured value in a scale corresponding to the current value in automatic mode. This allows you to increase the degree of readability of the value, and to avoid the situation when the scale of the device is designed for a large value, and the displayed value is small.

Depending on the purpose of the device, it can be modified in the form of an arrow, pointer circular, digital or columnar, when the scale height of the device depends on the displayed value. In addition, the devices have the ability to fix the maximum measured value in the form of a bright arrow, which can be reset by simply pressing the device.

Parameters such as the torque on the motor shaft, rotation speed and mechanical power are visualized using circular instruments, which are more convenient for the experimenter to perceive, with the maximum achieved values being fixed.

Thus, one more requirement for the stand has been implemented: it should be possible to set both constant load characteristics and variables (cyclic) in accordance with the wattmetrogram and a typical dynamogram deployed in time, on the stand console there should be an operative adjustment of the amplitude and period of the given dynamograms.

Simulation signals from sensors such as a wellhead pressure sensor and a flow meter are generated similarly to dynamometer signals.

The control system of the stand includes programmable logic controllers that solve several problems:

- in the process of testing, they participate in the processing of data received from the sensors;

- have the ability to control the frequency converter built into the control station;

- allow you to check the correct functioning of the embedded control algorithms for the machine - a rocker with their subsequent loading into the control system of the sucker rod pumping unit.

Thus, analog, discrete and digital control and management channels are implemented in the experimental stand. Analog channels are built on 16-bit on digital-to-analog converters (DAC) and analog-todigital converters (ADC) with a basic reduced error limit of no more than $0.25 \%$. The technical solutions incorporated in the design of the stand, as well as the 
flexibility of the control system operation algorithms, allow a wide range of studies with the use of various test objects.

\section{Benefits of a digital controller}

Increased control accuracy and system response speed are necessary to improve the accuracy of simulating the operating modes of the oil pumping unit and to check the response of the control system of the electric motor under test $[14,15]$. In addition, the preservation of the shape of the loading torque curve is of great importance, since this reflects the processes occurring on a real oil pumping unit, and any deviation can cause an erroneous reaction of the control system of the engine under test [16].

Figure 2 shows the operation of the loading system without the introduction of a regulator. The load torque set by the control system according to the selected curve is indicated by the Tz signal. The response of the system in the form of torque on the motor shaft measured by the torque transducer is shown by the Moment curve. The deviation of the generated torque on the motor shaft from the specified one is shown by the Delta curve.

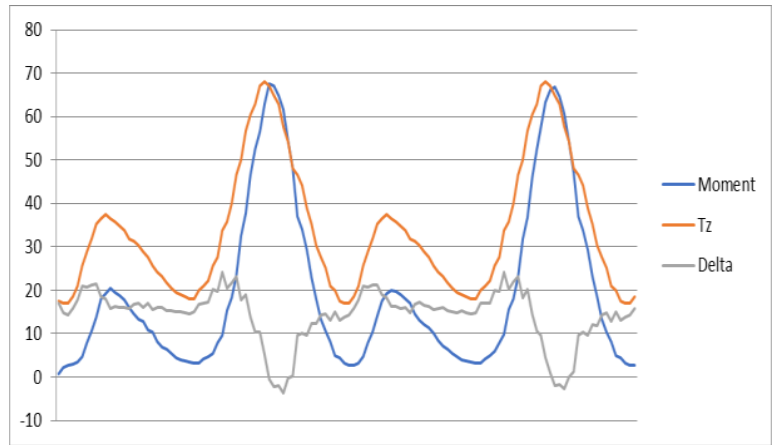

Fig. 2.Schedules of the system operation without the use of adjustments and regulators. Moment - the amount of moment measured by the torque sensor on the motor shaft; $\mathrm{Tz}$ - torque setting signal; Delta is the deviation of the torque on the shaft from the specified one.

In order to improve the accuracy of the loading system, a digital torque regulator on the shaft of the tested electric motor is introduced into the stand control system $[17,18,19]$. At the same time, the synthesis of a digital torque controller was carried out according to the criterion of dynamic accuracy with discrete approximation based on a bilinear transformation.

In this case, the transfer function has the form:

$$
W(s)=\frac{K_{\varepsilon}\left(T_{1} s+1\right)}{s^{2}\left(T_{2} s+1\right)}
$$

After discrete approximation of the controller, the transfer function in $\mathrm{z}$-form takes the form:

$$
W^{\mathrm{a}}(z)=\frac{B(z)}{D(z)}=\frac{b_{3} z^{3}+b_{2} z^{2}+b_{1} z+b_{0}}{d_{3} z^{3}+d_{2} z^{2}+d_{1} z+d_{0}}
$$

In this case, the equations of state:

$$
\begin{gathered}
x_{1}\left[(k+1) T_{0}\right]=x_{2}\left(k T_{0}\right) ; \\
x_{2}\left[(k+1) T_{0}\right]=x_{3}\left(k T_{0}\right) ; \\
x_{3}\left[(k+1) T_{0}\right]=-d_{0} x_{1}\left(k T_{0}\right)-d_{1} x_{2}\left(k T_{0}\right)-d_{2} x_{3}\left(k T_{0}\right)+\Delta u_{\alpha}\left(k T_{0}\right)
\end{gathered}
$$

and the output equations:

$$
\begin{gathered}
u\left(k T_{0}\right)=\left(b_{0}-d_{0} b_{3}\right) x_{1}\left(k T_{0}\right)+ \\
+\left(b_{1}-d_{1} b_{3}\right) x_{2}\left(k T_{0}\right)+\left(b_{2}-d_{2} b_{3}\right) x_{3}\left(k T_{0}\right)+b_{3} \Delta u_{\alpha}\left(k T_{0}\right)= \\
=-0,3845 x_{1}\left(k T_{0}\right)+0,7361 x_{2}\left(k T_{0}\right)-0,3516 x_{3}\left(k T_{0}\right)+1,0137 \Delta u_{\alpha}\left(k T_{0}\right) .
\end{gathered}
$$

The stand control system implements an algorithm of operation in the form of the obtained difference equations [20]. The block diagram of the regulator is shown in Figure 3. In general, the digital regulator is implemented in software in a hardware-software complex built into a personal computer, which monitors the parameters and controls the test bench. As a result, a digital controller based on a closed system was obtained.

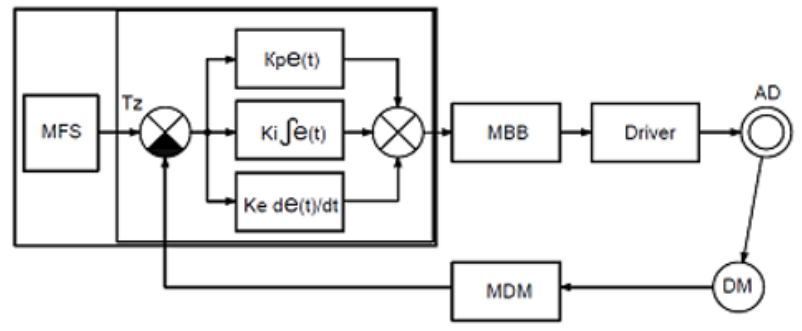

Fig. 3.Block diagram of the torque regulator on the shaft of the load motor of the test bench. MFS - signal conditioning module; Tz is the value of the given control signal; MBB signal input-output module as part of the stand control system; Driver - load frequency converter of the stand; AD - load electric motor; DM - torque sensor on the load motor shaft; MDM is a digital converter of the torque sensor.

\section{Digital controller application}

The structural diagram of the torque regulator on the motor shaft is shown in Figure 4. The digital regulator built into the computer (1) generates a control signal in digital form, fed to the digital-to-analog converter (2), and converted into a control signal of the frequency converter (3) in in the form of a unified current signal 4 ... $20 \mathrm{~mA}$. The frequency converter forms the load torque on the shaft of the electric motor (5), rigidly connected to the torque sensor (6) and the tested motor (4). The measured torque on the motor shaft is transmitted to the computer and to the input of the digital controller. 


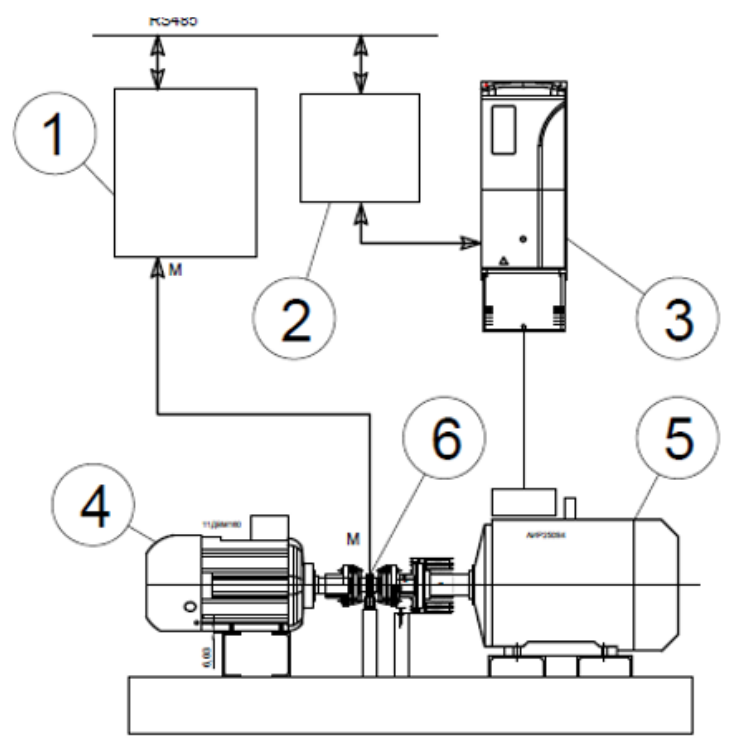

Fig. 4.Structural diagram of the implementation of the digital proportional-integral-differentiating (PID) controller in the test bench. 1 - personal computer of the test bench control system; 2 - digital-to-analog converter; 3 - frequency converter; 4 tested electric motor; 5 - load electric motor; 6 - torque sensor on the motor shaft.

With the introduction of the regulator into operation, a significant increase in the control accuracy and system response speed is observed, shown in Figure 5. Thus, the overshoot decreased to $10 \%$, and the control time became $0.1 \mathrm{~s}$, while the instrumental error was compensated.

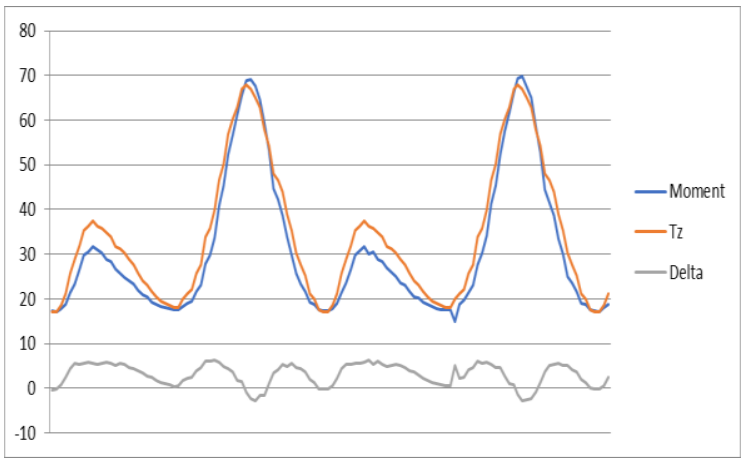

Fig. 5. Graphs of the system when using a digital PID controller.

The response of a digital torque regulator to a unit jump is the sum of the Dirac delta function obtained by differentiating a unit jump at time $t$, a constant component and a straight line corresponding to the integration operation and is shown in Figure 6. The difference between the transient response of the digital torque regulator and the transient response of the traditional PID controller is caused by the presence of two real poles, causing the exponential nature of the transient curve.

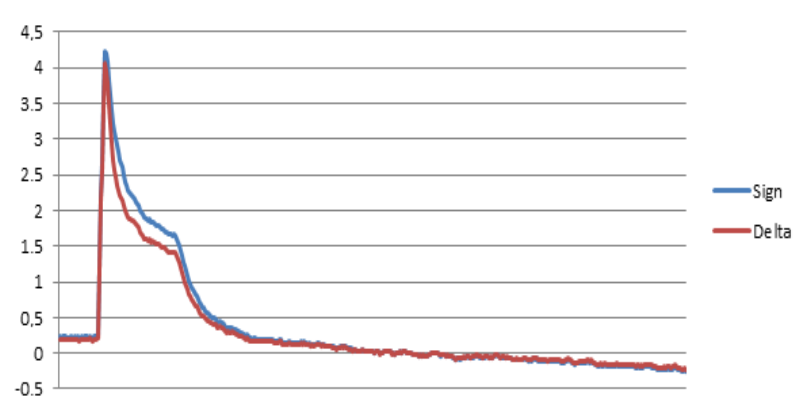

Fig. 6.Reaction of the digital torque regulator to a single jump. Sign - signal of the digital controller reaction to the deregulation signal; Delta - deregulation signal.

During the tests, the experimenter has the ability to select different types of dynamometer charts, which are presented in the form of an array of data showing the load on the rod depending on the length of travel of the polished rod, transmitted via a digital network to the control system. The operator has the ability to change the maximum and minimum values of the force on the rod. In addition, the experimenter simultaneously selects the type of variable torque on the shaft of the engine under test, which has an unambiguous connection with the characteristic of the dynamometer chart of the oil pumping unit.

\section{Conclusion}

The developed stand of the engines of pumping units, presented in the article, is more economical and simpler than real field tests. However, it also has disadvantages, the main of which is the low accuracy of torque control.

As a result of the synthesis and application of a digital torque regulator on the electric motor shaft, the control accuracy and the system response rate are significantly increased, the instrumental error is compensated, which gives additional opportunities in the implementation of the process of simulating a real operating installation of the oil pumping machine and the introduction of various faults to check the correct functioning of the electric drive control system.

\section{Acknowledgements}

The article was published as part of the project "Creating a Series of Electric Drives Based on Russian HighPerformance Synchronous Motors for Oil Pumping Units Using Wireless Data Communication Systems and an Adaptive Control System for Smart Fields", Agreement No. 074-11-2018-020 with the Ministry of Education and Science of the Russian Federation May 30, 2018

\section{References}

[1] A.N. Tsvetkov, V.Y. Kornilov, A.R. Safin, N.E. Kuvshinov, T.I. Petrov, A.G. Logacheva, An Experimental Bench for the Study of Electric Drives of a Horsehead Pump, Journal of Advanced Research in Dynamical and Control Systems 
(JARDCS) 12, 05, 1294-1298 ISSN: 1943-023X DOI: $10.5373 / J A R D C S / V 12 S P 5 / 20201888$

[2] P.V. Burkov, S.P. Burkova, V.Y. Timofeev, Justifying a method of balancing crank-and-rod mechanism of mining roadheader, Applied Mechanics and Materials 682, 270-275 (2014)

[3] V.Yu. Kornilov, A.I. Mukhametshin, A.N. Tsvetkov, The system of automated control of the energy characteristics of the asynchronous electric drive of sucker rod pumping units, Nonlinear World 6, 33-39 (2017)

[4] A.N. Tsvetkov, A.R. Safin, I.V. Ivshin, T.I. Petrov, R.Sh. Misbakhov, V.Yu. Kornilov, Adaptive Control System of the Pumping Unit, International Journal of Engineering and Advanced Technology (IJEAT) 8, 5S3 (July 2019) ISSN: 2249-8958

[5] E.I. Gracheva, O.V. Naumov, A.N. Gorlov, Modelling Characteristics of Reliability LowVoltage Switching Devices on the Basis of Random Checks on the Example of Contactors, Proceedings - 2019 1st International Conference on Control Systems, Mathematical Modelling, Automation and Energy Efficiency, SUMMA 2019, 8947595, 641643 (2019)

[6] F. Sarapulov, V. Frizen, I. Smolyanov, E. Shmakov, Dynamic study of thermal characteristics of linear induction motors, 15th International Conference on Electrical Machines, Drives and Power Systems, ELMA 2017 - Proceedings, 414-418 (2017)

[7] L. Dong, X. Han, L. Hua, J. Lan, W. Zhuang, Effects of the rotation speed ratio of double eccentricity bushings on rocking tool path in a cold rotary forging press, Journal of Mechanical Science and Technology 29, 4, pp. 1619-1628 (2015)

[8] L.L. Myagkov, S.M. Sivachev, E.E. Strizhov, S.P. Chirsky, Topological optimization of a highperformance diesel piston, Dvigatelestroyeniye 2, 3$10(2018)$

[9] L. Saihi, A. Boutera, Robust Sensorless Sliding Mode Control of PMSM with MRAS and Luenberger Extended Observer, 2016 8th International Conference on Modelling, Identification and Control (ICMIC 2016), 48-57 (2016)

[10] K.F. Fozao, M. Lissouck, F. Lontsi, A. Ngasa, N. Mbanda, Hands-on model of sucker rod pumping facility for oil well production, Journal of Petroleum and Gas Engineering 6, 45-53 (2015)

[11] T. Lindh, J.-H. Montonen, M. Grachev, M. Niemela, Generating surface dynamometer cards for a suckerrod pump by using frequency converter estimates and a process identification run, International Conference on Power Engineering, Energy and Electrical Drives, 7266353, 416-420 (September 2015)

[12] S. Miric, A. Tuysuz, J.W. Kolar, Comparative evaluation of linear-rotary actuator topologies for highly dynamic applications, 2017 IEEE
International Electric Machines and Drives Conference, IEMDC 2017 (2017)

[13]D. Wang, D. Zhang, X. Du, X. Wang, Thermal Identification, Model, and Experimental Validation of a Toroidally Wound Mover Linear-Switched Reluctance Machine, IEEE Transactions on Magnetics 54, 3 (2018)

[14] M. Cossale, G. Bramerdorfer, G. Goldbeck, M. Kitzberger, D. Andessner, W. Amrhein, Modeling the Degradation of Relative Permeability in Soft Magnetic Materials, 2018 IEEE Transportation and Electrification Conference and Expo, ITEC 2018, 744-748 (2018)

[15] H. Li, Y. Qian, S. Asgarpoor, J. Bradley, PMSM current management with overcurrent regulation, Conference Proceedings - IEEE Applied Power Electronics Conference and Exposition APEC, 1848-1852 (March 2019).

[16] X. Bei, X. Zhu, D.W. Coit, A risk-averse stochastic program for integrated system design and preventive maintenance planning, European Journal of Operational Research 276, 2, 536-548 (2019)

[17] S. Morimoto, K. Kawamoto, M. Sanada, et. al., Sensorless control strategy for salient-pole PMSM based on extended EMF in rotating reference frame, Proc. 2001 IEEE IAS Annual Meeting 4, 2637-2644 (2011)

[18]C. Li, I.Y. Kim, Multi-material topology optimization for automotive design problems, Proceedings of the Institution of Mechanical Engineers, Part D: Journal of Automobile Engineering 232, 14, 1950-1969 (2018)

[19] V.D. Kovshov, M.E. Sidorov, S.V. Svetlakova, Simulation of the dynamogram of the rocking machine, Leaks in valves, Oil and gas business 3, 47-54 (2005)

[20] I.I. Mazein, A.N. Ustinov, M.V. Tyaktev, A.A. Rybin, D.I. Shishlyannikov, M.M. Tyaktev, The results of pilot tests of promising drives for suckerrod pumping units Mining equipment and electromechanics 9, 8-14 (2016) 